\title{
Spatial and temporal genetic variability in French populations of the peach-potato aphid, Myzus persicae
}

\author{
T Guillemaud ${ }^{1}$, L Mieuzet ${ }^{2}$ and J-C Simon ${ }^{2}$ \\ ${ }^{1}$ Equipe 'Ecotoxicologie et Résistance aux Insecticides', UMR 1112, INRA-UNSA, Antibes F-06606, France; 'Equipe 'Biologie et \\ Génétique des Populations d'Insectes' UMR BIO3P, INRA B.P. 29, F-35653 Le Rheu, Cedex, France
}

\begin{abstract}
The peach-potato aphid, Myzus persicae (Sulzer), has a complex reproductive mode in which some lineages reproduce by continuous parthenogenesis, whereas others reproduce sexually once a year. The climate is thought to act directly on the reproductive mode, because sexual eggs are the only form that can resist frost in cold regions. Sexual reproduction necessitates an obligatory host alternation that may result in long-distance dispersal. Here, we examined the genetic variability at seven microsatellite loci of populations of $M$. persicae in France, where both reproductive modes occur. We provide clear genetic evidence that the breeding
\end{abstract}

system affects genotypic variability, as cyclically parthenogenetic aphids are far more variable than their obligately parthenogenetic counterparts. A temporal decrease in genetic variability and a temporal genetic differentiation effect suggest the existence of selective factors that play an important role in shaping the genetic structure of $M$. persicae populations. Lastly, differences in the population structure between reproductive modes suggest that the migration associated with the change of host during sexual reproduction lowers the level of population differentiation. Heredity (2002) 91, 143-152. doi:10.1038/sj.hdy.6800292

Keywords: aphids; microsatellite; cyclical parthenogenesis; clonal reproduction; sex; migration

\section{Introduction}

Reproductive mode has important consequences for the evolution of organisms. Sexual reproduction generates diversity through recombination, and thus may be selected in the long term. On the contrary, in the shortterm, sexual reproduction displays a two-fold cost when compared to asexual reproduction, as asexual organisms transmit their genes twice as efficiently (Maynard Smith, 1998). The problem of maintaining sexual reproduction is particularly relevant in species that display both reproductive modes. In such species, like cladocerans (Hebert, 1981), rotifers (Butlin, 2000) or aphids (Simon et al, 2002), the coexistence of both reproductive modes results from the loss of sexuality in some lineages. An understanding of the genetical consequences of both reproductive modes in these organisms may help to explain the maintenance of sex.

Like many aphid species, the peach-potato aphid, Myzus persicae (Sulzer), has a complex and variable breeding system. During each annual cycle, cyclically parthenogenetic $M$. persicae aphids reproduce asexually several times on herbaceous plants (secondary hosts) and once sexually on peach trees (Prunus persica L.). Obligately parthenogenetic aphids have lost the ability to reproduce sexually (Figure 1), but have retained the ability to produce some males (Blackman, 1972). In

Correspondence: T Guillemaud, Equipe Ecotoxicologie et Résistance aux Insecticides, UMR 1112, INRA-UNSA, Antibes F-06606, France.

E-mail: guillem@antibes.inra.fr

Received 19 August 2002; accepted 21 February 2003 optimal conditions, a parthenogenetic generation (from birth to the mature adult) is accomplished within 8-10 days; thus more than 20 asexual generations can precede the sexual phase in cyclically parthenogenetic aphids. In temperate regions, like France, both reproductive modes can coexist in sympatry (Blackman, 1974). Blackman (1974) proposed that the geographical distribution of reproductive modes results from a selective pressure: the climate. $M$. persicae can reproduce by apomictic parthenogenesis most of the year on numerous species of secondary hosts (Blackman and Eastop, 1984). In places where the winter is mild, obligately parthenogenetic aphids can spend the winter on secondary hosts (Blackman, 1974). However, in regions where the winter is severe, continuously parthenogenetic aphids cannot survive outdoors. The production of eggs by cyclically parthenogenetic aphids may constitute a selective advantage in cold regions where peach trees are available, as eggs are the only forms that can resist frost, whereas it may be more costly in mild regions compared to obligate parthenogenesis. This hypothesis was subsequently formalised (Rispe et al 1998b; Rispe and Pierre, 1998) and has been validated in other aphid species such as the grain aphid, Sitobion avenae (F.) (Dedryver et al, 2001).

The different life cycle forms of $M$. persicae are detailed in Figure 1. In autumn, cyclically parthenogenetic aphids give birth to gynoparae (precursor forms of sexual females) and winged males that both fly to peach trees, where gynoparae give birth to sexual females. Mating occurs on these trees and sexual females lay eggs that hatch by the beginning of spring. In Europe, most peach 
trees grow in commercial orchards in southern regions, but some of them are also found further north, for example, in private gardens. Thus, depending on peach tree availability, males and precursors of sexual females may have to occasionally fly long distances because of host alternation associated with sexual reproduction. In early spring, after a few parthenogenetic generations, aphids migrate from primary to secondary hosts. During spring and summer, both obligately and cyclically parthenogenetic aphids produce winged morphs that spread among secondary hosts, and in mild regions, obligately parthenogenetic females can also participate in the autumn flight to disperse among secondary hosts. Therefore in $M$. persicae, three main flight activities take place per year, and one of them, the autumn flight, may correspond to long-distance migration because of the necessity to change host for sexual reproduction.

A number of general genetic features are expected when analysing obligately and cyclically parthenogenetic populations of the same species. (a) Genotypic variability should be higher in cyclically than in obligately parthenogenetic populations, as mutations
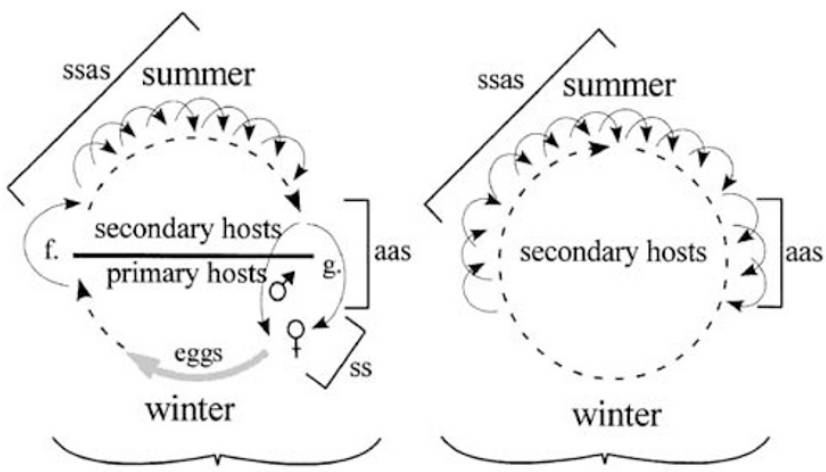

cyclically parthenogenetic aphids obligately parthenogenetic aphids

Figure 1 Life cycles of $M$. persicae. The continuous black arrows indicate the migration of winged aphids. The dashed black arrows indicate several parthenogenetic generations. The grey arrow corresponds to the development of the eggs. Sampling periods (autumn, spring-summer) and sample characteristics (aerial and sexual) are indicated for both reproductive modes: 'ssas' corresponds to spring-summer aerial samples, 'aas' to autumn aerial samples and 'ss' to sexual samples. are the only source of variability in the absence of recombination (eg Delmotte et al, 2002), (b) ancient clonal organisms should show a heterozygous excess and their heterozygosity should be higher than that of sexually reproducing lineages as a consequence of accumulated mutations (Normark, 1999; Butlin, 2000; Judson and Normark, 2000; Mark Welch and Meselson, 2000; Delmotte et al, 2002), (c) linkage disequilibrium should be more frequent in obligately parthenogenetic populations than in cyclically parthenogenetic ones, (d) drift and/or selection may strongly affect neutral genetic variability during the parthenogenetic phase of both life cycles due to the absence of recombination and the rapid rate of increase during clonal reproduction and (e) in the specific case of $M$. persicae, a larger differentiation is expected between strictly asexual populations than between cyclically parthenogenetic populations because of the migration associated with the change of hosts.

In this paper, we analysed the effects of the reproductive mode on the genetic variability of $M$. persicae and tested the hypotheses described above. A microsatellite analysis of $M$. persicae individuals collected in France in suction (aerial) traps and on primary hosts was performed to answer the following questions: Can we infer the reproductive modes from microsatellite data and can we validate hypotheses (a)-(c)? What is the extent of genetic differentiation and migration among populations of $M$. persicae in France and do they depend on the reproductive mode (hypothesis (e))? Does this genetic structure imply drift or selection during the parthenogenetic phase of the life cycle (hypothesis (d))?

\section{Materials and methods}

\section{Aphid samples}

Two sets of aphids were sampled by different methods from the air and from peach trees.

Aerial samples: The first set of aphids were collected in $12.2 \mathrm{~m}$ high suction traps of the French Agraphid suction trap network (Hullé, 1991). Four traps located at Colmar in north eastern France, Valence in southern France, Loos-en-Gohelle in northern France and Le Rheu in western France were used (Table 1 and Figure 2). An additional trap located near Montpellier in southern

Table 1 Characteristics of the samples of Myzus persicae

\begin{tabular}{|c|c|c|c|c|c|c|c|}
\hline Location & Set type & Longitude & Latitude & $\mathrm{N}$ & Name & Date & $\mathrm{n}$ \\
\hline Montpellier & Suction Trap & $3^{\circ} 53^{\prime} \mathrm{E}$ & $43^{\circ} 37^{\prime} \mathrm{N}$ & 143 & & & \\
\hline Valence & Suction Trap & $4^{\circ} 53^{\prime} \mathrm{E}$ & $44^{\circ} 56^{\prime} \mathrm{N}$ & 242 & $\begin{array}{l}\text { Val_1 } \\
\text { Val_2 }\end{array}$ & $\begin{array}{l}\text { Spring-summer } \\
\text { Autumn }\end{array}$ & $\begin{array}{l}40 \\
44\end{array}$ \\
\hline Le Rheu & Suction Trap & $1^{\circ} 47^{\prime} \mathrm{W}$ & $48^{\circ} 06^{\prime} \mathrm{N}$ & 94 & $\begin{array}{l}\text { LR_1 } \\
\text { LR_2 }\end{array}$ & $\begin{array}{l}\text { Spring-summer } \\
\text { Autumn }\end{array}$ & $\begin{array}{l}39 \\
34\end{array}$ \\
\hline Colmar & Suction Trap & $7^{\circ} 21^{\prime} \mathrm{E}$ & $48^{\circ} 04^{\prime} \mathrm{N}$ & 261 & $\begin{array}{l}\text { Col_1 } \\
\text { Col_2 }\end{array}$ & $\begin{array}{l}\text { Spring-summer } \\
\text { Autumn }\end{array}$ & $\begin{array}{l}45 \\
45\end{array}$ \\
\hline Loos-en-Gohelle & Suction Trap & $2^{\circ} 47^{\prime} \mathrm{E}$ & $50^{\circ} 27^{\prime} \mathrm{N}$ & 24 & $\begin{array}{l}\text { Loos_1 } \\
\text { Loos_2 }\end{array}$ & $\begin{array}{l}\text { Spring-summer } \\
\text { Autumn }\end{array}$ & $\begin{array}{r}16 \\
4\end{array}$ \\
\hline Fréjus & Peach Tree & $6^{\circ} 44^{\prime} \mathrm{E}$ & $43^{\circ} 26^{\prime} \mathrm{N}$ & & Fréj & 3 November & 6 \\
\hline Roquebrune/Argens & Peach Tree & $6^{\circ} 38 \mathrm{E}$ & $43^{\circ} 26 \mathrm{~N}$ & & Roq & 3 November & 23 \\
\hline Carros & Peach Tree & $7^{\circ} 11^{\prime} \mathrm{E}$ & $43^{\circ} 47^{\prime} \mathrm{N}$ & & Car & 5 November & 16 \\
\hline Antibes & Peach Tree & $7^{\circ} 07^{\prime} \mathrm{E}$ & $43^{\circ} 34 \mathrm{~N}$ & & Ant & 7,15 November & 5 \\
\hline Avignon & Peach Tree & $4^{\circ} 48 \mathrm{E}$ & $43^{\circ} 56 \mathrm{~N}$ & & Avi & 14-17 November & 30 \\
\hline
\end{tabular}

$N$ is the total number of aphids caught in each suction trap in 2000 and $n$ is the number of aphids analysed in the genetic study. 


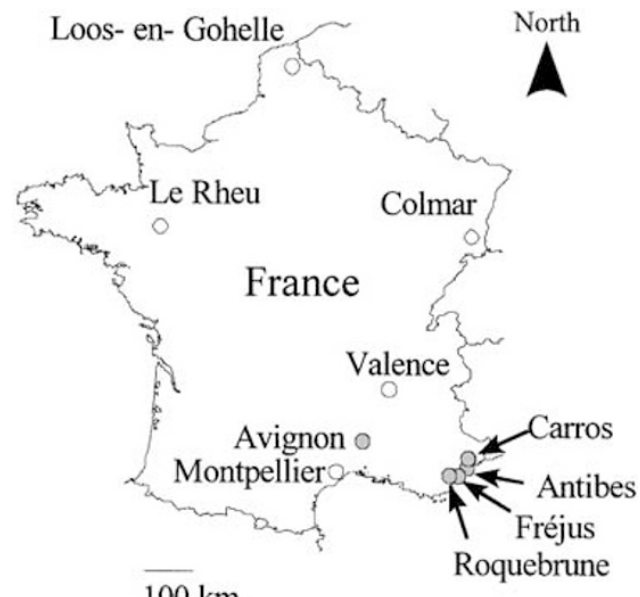

$100 \mathrm{~km}$

Figure 2 Geographical locations of the 10 sampling sites. The open circles correspond to aerial samples.

France was employed for the dynamics analysis. Winged males and females were counted and collected each day in the year 2000, and were kept in $70 \%$ ethanol prior to genetic analysis. For the population genetic analysis, samples were divided into subsamples that corresponded to distinct flight activities (Figure 1). Early spring and summer flight activities were not easily distinguishable in 2000 (Figure 3, see results), therefore, we considered only two flight periods: (1) spring and summer and (2) autumn. Samples from Colmar, Loos-en-Gohelle, Le Rheu and Valence were thus divided into two parts. The first part (the springsummer flight) corresponded to the period between 8th May (week 19) and 31st August 2000 (week 35). The second one (autumn flight) started on 1st September (week 36) and ended on the last day of 2000 (week 52). Subsets of $M$. persicae from these four traps (the Montpellier trap was not used for the genetic analysis) were randomly chosen among all of the aphids caught in each period for the genetic study (Table 1 and Figure 3). The sample sizes of these subsets corresponded, respectively, to $35,78,34$, and $83 \%$ of the total number of $M$. persicae caught in Valence, Le Rheu, Colmar and Loos-en-Gohelle in 2000.

Peach orchard samples: In France, peach trees generally grow in southern regions. Five samples of aphids were collected in November 2000 from peach orchards located in the Côte d'Azur and Provence in southern France (Table 1 and Figure 2). Males, wingless sexual females and winged females (thought to be precursors of sexual females) were sampled. These samples will be referred to as sexual samples hereafter. All aphids were stored at $-80^{\circ} \mathrm{C}$ until DNA extraction.

In summary, the three types of samples should a priori include different proportions of aphids with different reproductive modes: (1) in late spring and summer, both cyclically and obligately parthenogenetic aphids disperse among secondary hosts; therefore, the spring-summer aerial samples should correspond to a mixture of both reproductive modes and (2) autumn aerial samples should a priori correspond to cyclically parthenogenetic aphids in cold regions and to obligately parthenogenetic aphids in mild regions. The aerial samples collected in
Genetic structure of French peach-potato aphids

T Guillemaud et al

Valence and Le Rheu should be mainly constituted of obligately parthenogenetic aphids because of their geographical locations. Lastly, (3) aphids caught on the primary host are considered to be cyclically parthenogenetic aphids.

\section{Microsatellite analysis}

Genomic DNA was obtained from single aphids as described in Sunnucks and Hales (1996). DNA was resuspended in $50 \mu \mathrm{l} \mathrm{H}_{2} \mathrm{O}$.

Each aphid was genotyped using seven microsatellite loci: three (Myz2, Myz35, Myz40) were isolated from $M$. percicae (Sloane et al, 2001, Gavin Malarky, unpublished), three (S16b, S17b, S24) from Sitobion miscanthi (Takahashi) (Wilson and Sunnucks, unpublished) and one (R5.180) from Rhopalosiphum padi (L.) (Simon et al, 2001).

The microsatellites were amplified in a $15 \mu \mathrm{l}$ volume containing 0.1 units of Taq polymerase (Promega), $1 \times \mathrm{MgCl}_{2}, 200 \mu \mathrm{M} \mathrm{dNTP}, 0.2 \mathrm{mM}$ of each primer and $1 \mu \mathrm{l}$ of the diluted aphid DNA. PCR reactions were performed in a PCR Express machine (Hybaid, Inc) as follows: initial denaturation at $94^{\circ} \mathrm{C}$ for $2 \mathrm{~min}$ followed by 35 cycles of denaturation at $94^{\circ} \mathrm{C}$, annealing temperature depending on the locus and elongation at $72^{\circ} \mathrm{C}$, each for $40 \mathrm{~s}$. Microsatellite products were then loaded onto a denaturing polyacrylamide gel and visualised by silver staining as described by Haack et al (2000). Allele sizes were estimated by use of a sequencing size ladder (sequence of pGEM - 3Zf(+) vector PROMEGA).

\section{Analysis of genetic data}

Microsatellite variability: Allele frequencies, number of alleles and heterozygosity were calculated using the GENEPOP (ver. 3.3) software (Raymond and Rousset, 1995a). Linkage disequilibrium between loci within each population and departure from Hardy-Weinberg equilibrium at each locus were tested using the pseudoexact test procedures in GENEPOP 3.3. Individual multilocus heterozygosity was calculated on one individual without missing data representative of each genotype per sample considered (one copy per genotype).

Between sample analysis: Differences in the genetic structure between samples and between sample groups were analysed by testing for genic and genotypic differentiation (pseudoexact test described in Raymond and Rousset, 1995b), and by calculating estimators of Fst (Weir and Cockerham, 1984) using GENEPOP 3.3. Some reservation must be made on the use of $F$ statistics to study a species with a mixture of cyclically and obligately parthenogenetic individuals. However, theoretical work has, so far, failed to produce specifically adapted tools, and if our results are to be compared with other population genetics studies on aphids (eg Delmotte et al, 2002; Llewellyn et al, 2003), it is important to use common statistical methods. The Isolde program from the GENEPOP package was used to perform Mantel tests of independence between matrices (genetic versus geographical or temporal distance matrices).

General statistical methods: Pseudoexact tests of homogeneity on $\mathrm{R} \times \mathrm{C}$ contingency tables were performed using the Struc program in the GENEPOP 


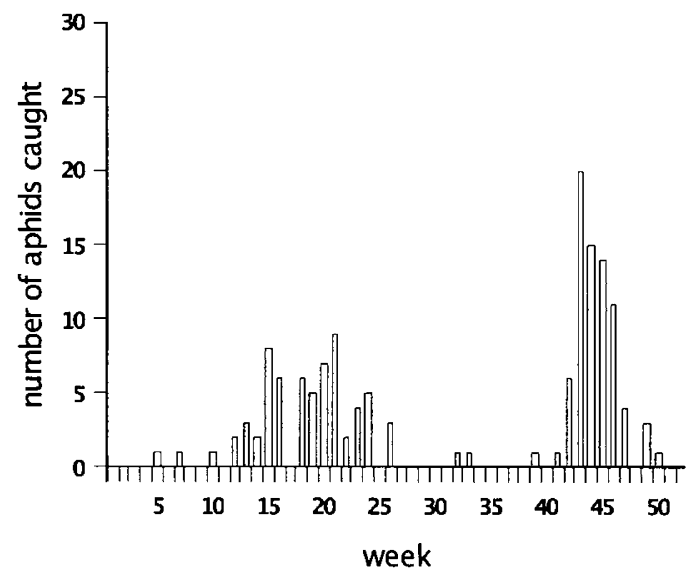

Loos-en-Gohelle
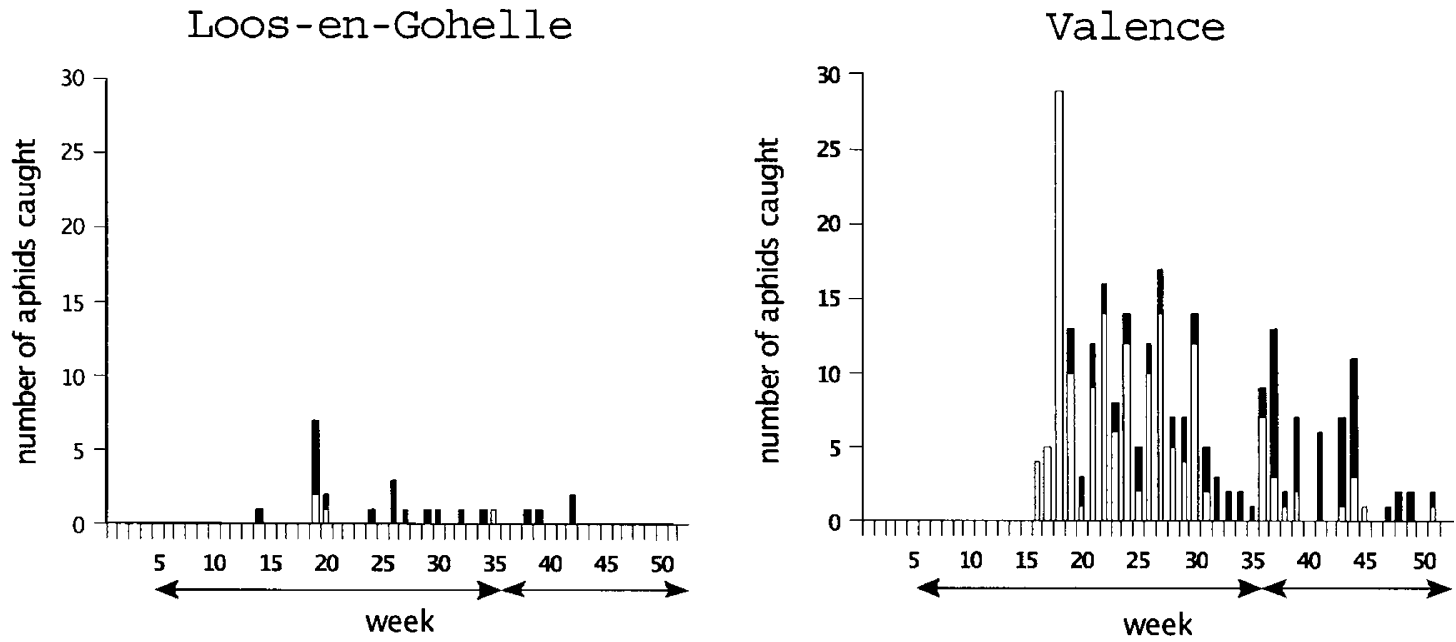

Le Rheu
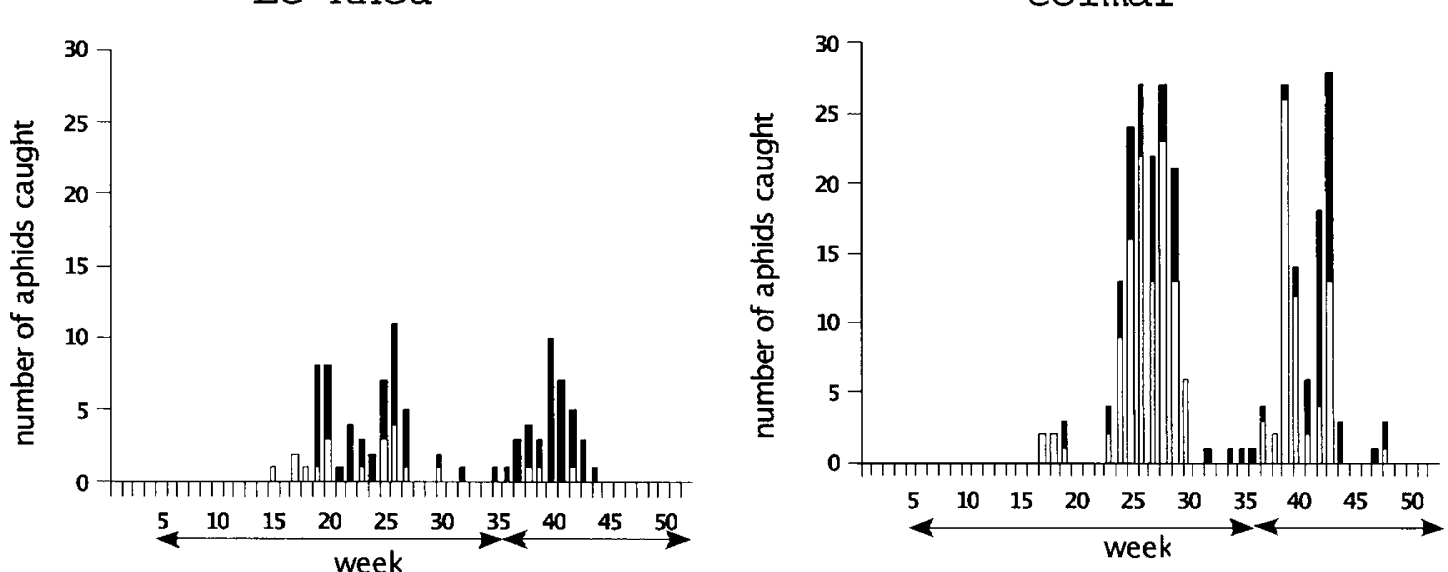

Figure 3 Weekly aerial abundances of M. persicae (males and females pooled) caught at $12.2 \mathrm{~m}$ in 2000 . The black bars show the number of aphids analysed in the genetic study, and the arrows delimit the two periods considered.

3.3 package. Overall significance of several independent tests was calculated using Fisher's method (Sokal and Rohlf, 1995, pp 794-797). Sequential Bonferroni correction was applied for nonorthogonal (pairwise differentiation and linkage disequilibrium) and for table wide tests (Sokal and Rohlf, 1995, pp 241-242).

\section{Results}

Variability of temporal dynamics

The number of aphids caught in each trap in 2000 was highly variable between sites (Table 1 and Figure 3), 
ranging from 24 individuals in Loos to 261 in Colmar. The proportion of males was $6.5 \%$ in Colmar, $4.9 \%$ in Montpellier, $2.1 \%$ in Le Rheu, $0.4 \%$ in Valence and $0 \%$ in Loos-en-Gohelle. These proportions were significantly different between sites (Fisher's exact test, $P=2.2 \times$ $\left.10^{-3}\right)$. Temporal dynamics were different between traps, $M$. persicae individuals were captured sooner in the spring and later in the autumn in southern traps than in northern traps (Figure 3 ). The spring and summer flights were hardly distinguishable in most traps (Figure 3), whereas the autumn flight was clearly observable in all five traps although its quantitative importance was variable between traps. This variation could not be attributed to the geographic location of the traps.

\section{Within sample genetic diversity}

The number of alleles at the microsatellite loci ranged from four at locus S.24 to 18 at locus R5.180. All loci were polymorphic in all samples, except locus S.24 in the Loos-en-Gohelle samples. The genotypes of locus $\mathrm{S} .17 \mathrm{~b}$ could not be obtained for the two samples from Colmar.

Analysis of genotypic disequilibrium between each pair of loci in each sample did not reveal any significant linkage in sexual samples (Table 2). However, significant associations were frequently found in aerial samples. The number of loci showing significant linkage disequilibrium increased between the two periods in Valence and Le Rheu and decreased in Colmar and Loos. Among samples of equal size, the autumn flight sample from Colmar presented the lowest number of loci in linkage disequilibrium.

Although Hardy-Weinberg $(\mathrm{H}-\mathrm{W})$ equilibrium was not expected in groups of individuals that had been reproducing parthenogenetically for several generations before sampling, we tested for this equilibrium and measured the corresponding deviation in each sample (Table 2). Three sexual samples did not deviate from $\mathrm{H}-$ $\mathrm{W}$ equilibrium, and two samples presented a significant heterozygote deficiency. $\mathrm{H}-\mathrm{W}$ equilibrium was rejected in all aerial samples and generally corresponded to heterozygote deficiency.

No heterogeneity in observed heterozygosities $\left(H_{o}\right)$ was found whatever the grouping of the samples. Individual heterozygosities, defined as the proportions of heterozygous loci per individual representative of each genotype (ie using the 'one copy per genotype' method), were not significantly different between samples (Fisher's exact test, $P=0.76$ ), between both periods in aerial samples $(P=0.75)$ or between each period and the sexual samples ( $P>0.05$ for both comparisons).

The mean number of alleles per locus and per sample was significantly higher in aerial samples collected in spring-summer $\left(n_{\text {all }}=4.58 \pm 0.49\right)$ than in autumn $\left(n_{\text {all }}=3.49 \pm 0.38\right.$; Wilcoxon's signed rank test on period means, $N=7, T+=28, P=0.016)$ and in sexual samples $\left(n_{\text {all }}=3.34 \pm 0.28 ; N=7, T+=28, p=0.016\right)$. Aerial samples contained $92 \%$ of the number of alleles found in the sexual samples, and $88 \%$ of the alleles found in autumn aerial samples were common to spring-summer aerial samples. Conversely, $30 \%$ of the total number of alleles found in spring-summer samples were private alleles. Therefore, an impoverishment through time was detectable at the allelic level.

Table 2 shows the number of different genotypes per sample when considering the 237 individuals without missing data (including the samples from Colmar that were characterised at six loci). Among these individuals, 163 multilocus genotypes were distinguished. In sexual samples, 63 different genotypes were found among 64 individuals. In aerial samples, 12 genotypes were found more than once. Le Rheu was the location where repeated genotypes were the most frequent with only eight genotypes present in a single copy in the 50 aphids without missing data. Conversely, the number of repeated genotypes was lowest at Colmar, with 37 different genotypes among 42 individuals without missing data. The only genotype that was common to aerial and sexual samples was shared by an individual

Table 2 Within sample variability in M. persicae

\begin{tabular}{|c|c|c|c|c|c|c|c|c|c|c|}
\hline \multirow[t]{2}{*}{ Sample } & \multicolumn{3}{|c|}{$\mathrm{n}_{\text {all }}$} & \multirow[b]{2}{*}{$\mathrm{n}_{\mathrm{g}} / \mathrm{n}^{\prime}$} & \multicolumn{2}{|c|}{$\mathrm{H}_{\mathrm{o}}$} & \multicolumn{2}{|c|}{$\mathrm{H}_{\text {ind }}$} & \multirow[b]{2}{*}{$D L$} & \multirow[b]{2}{*}{$\mathrm{f}$} \\
\hline & $\mathrm{n}$ & mean & $S E$ & & mean & $S E$ & mean & $S E$ & & \\
\hline Val_1 & 40 & 5.71 & 1.19 & $26 / 30$ & 0.39 & 0.07 & 0.42 & 0.06 & $5 / 21$ & $0.31^{*}$ \\
\hline Val_2 & 44 & 4.29 & 0.78 & $18 / 33$ & 0.43 & 0.11 & 0.43 & 0.08 & $10 / 21$ & $0.07^{*}$ \\
\hline LR_1 & 39 & 5.29 & 1.13 & $11 / 20$ & 0.38 & 0.11 & 0.35 & 0.09 & $3 / 21$ & $0.22^{*}$ \\
\hline LR_2 & 34 & 3.43 & 0.84 & $7 / 30$ & 0.47 & 0.15 & 0.38 & 0.11 & $5 / 13$ & $-0.39^{*}$ \\
\hline Col_1 & 45 & 4.33 & 0.76 & $14 / 15$ & 0.39 & 0.11 & 0.43 & 0.07 & $8 / 15$ & $0.01^{*}$ \\
\hline Col_2 & 45 & 3.83 & 0.95 & $24 / 27$ & 0.40 & 0.11 & 0.38 & 0.07 & $2 / 15$ & $0.13^{*}$ \\
\hline Loos_1 & 16 & 3 & 0.49 & $11 / 14$ & 0.40 & 0.10 & 0.42 & 0.08 & $0 / 15$ & $0.12^{*}$ \\
\hline Loos_2 & 4 & 2.43 & 0.37 & $4 / 4$ & 0.29 & 0.09 & 0.29 & 0.11 & $0 / 15$ & $0.47^{*}$ \\
\hline Fréj & 6 & 2.57 & 0.30 & $5 / 5$ & 0.56 & 0.12 & 0.54 & 0.06 & $0 / 10$ & $-0.19 \mathrm{NS}$ \\
\hline Roq & 23 & 3.86 & 0.63 & $20 / 21$ & 0.46 & 0.09 & 0.49 & 0.08 & $0 / 21$ & $0.17^{*}$ \\
\hline Car & 16 & 4 & 0.79 & $12 / 12$ & 0.45 & 0.06 & 0.46 & 0.08 & $0 / 21$ & $0.20^{*}$ \\
\hline Ant & 5 & 2.57 & 0.37 & $4 / 4$ & 0.51 & 0.09 & 0.43 & 0.20 & $0 / 9$ & $-0.07 \mathrm{NS}$ \\
\hline Avi & 30 & 3.71 & 4.28 & $22 / 22$ & 0.48 & 0.08 & 0.46 & 0.09 & $0 / 21$ & $0.02 \mathrm{NS}$ \\
\hline
\end{tabular}

$n$ is the sample size, $n_{\text {all }}$ the number of alleles, $n_{g}$ the number of different genotypes calculated over $n^{\prime}$, the number of individuals without missing data. $H_{o}$ is the observed and $H_{\text {ind }}$ the individual heterozygosity. $D L$ is the number of pairs of loci showing a significant linkage disequilibrium out of the number of possible tests. $f$ is the estimate of the Fis parameter. The mean and the standard error are given for $H_{o}$ $H_{\text {ind }}$ and $n_{\text {all }}$. The star $\left(^{*}\right)$ indicates that Hardy-Weinberg equilibrium was rejected over all loci at the $5 \%$ level after correction for multiple tests. 
from the Colmar autumn sample and by two females from the Roquebrune sexual sample. The proportion of different genotypes (ratio $n_{g} / n_{\text {ind }}$ ) was larger in sexual samples (0.98) than in spring-summer samples (0.75) and was larger in spring-summer than in autumn aerial samples (0.54) (Fisher's exact test, $P<10^{-3}$ for each comparison). The four most frequent multilocus genotypes (G1, G2, G3 and G4) were present 23, 22, 13 and 6 times in the samples, respectively. The frequency of G1 and G4 increased significantly from 6.4 to $19 \%$ and from 0 to $6.3 \%$, respectively, between spring-summer and autumn. The frequencies of G2 and G3 did not vary significantly with time.

In summary, we observed maximal genotypic variability in sexual samples, the number of genotypes being almost equal to the number of individuals with no linkage disequilibrium, and few departures from $\mathrm{H}-\mathrm{W}$ equilibrium. On the contrary, repeated genotypes, linkage disequilibrium and departure from H-W equilibrium were frequent in most aerial samples. The Colmar autumn sample showed intermediate characteristics between the sexual and the aerial samples.

\section{Genetic differentiation between samples}

Spatial genetic structure was analysed by testing for homogeneity of genotypic (Table 3) and genic frequencies between samples. Tests on genic and genotypic frequencies gave basically the same results, thus only genotypic differentiation results are presented. Differentiation between pairs of samples was measured by Fst estimators (Table 3). No significant differentiation was found on a small geographical scale (Côte d'Azur geographic distances $<60 \mathrm{~km}$ ), and Fst estimates were generally low (Table 3). These samples were grouped for subsequent tests. On a regional scale (distances of about $150-200 \mathrm{~km})$, we found a low but significant genetic differentiation between Côte d'Azur and Avignon orchards. On the national scale, the comparison of autumn samples, including sexual samples and aerial samples, revealed significant genetic differentiation, with substantial Fst estimates. The estimated Fst between the Colmar autumn and sexual samples were rather low $(4.6 \pm 2.6 \%)$ when compared to that between other aerial samples and sexual samples $(10.7 \pm 2.7 \%)$. All aerial samples were significantly differentiated, with moderate and high Fst estimates in spring and autumn, respectively.

\section{Temporal genetic differentiation between samples}

For each suction trap, we compared the two periods corresponding to the two main flight activities: springsummer and autumn (Table 3). Genotypic/genic differentiation was significant in Valence and Le Rheu with Fst estimates of 3 and $8 \%$, respectively. We performed an 'isolation by time' test in each suction trap, that is we tested the null hypothesis of independence between genetic distances and time between individual samplings. Our sampling scheme allowed us to test this hypothesis because the aphids were caught every day for several months, and because temporal coordinates (day of capture) were assigned to each aphid. The results of the 'isolation by time' test were significant in Valence and Le Rheu $(\hat{a}(r)=0.45+0.0026 r$, Mantel test with 20000 permutations, $P=0.009 ;$ and $\hat{a}(r)=-0.13+0.0027 r$, $P=0.0008$, respectively).

In summary, all aerial samples were differentiated from each other and the level of differentiation increased between summer and autumn. Sexual samples were moderately differentiated or undifferentiated. Sexual and most autumn aerial samples (except that of Colmar) were strongly differentiated. Differentiation was observed in Le Rheu and Valence between autumn and summer, and

Table 3 Analysis of genetic population differentiation in M. persicae

\begin{tabular}{|c|c|c|c|c|c|c|c|c|c|c|c|c|c|}
\hline & \multicolumn{9}{|c|}{ Autumn samples } & \multicolumn{4}{|c|}{ Spring-summer samples } \\
\hline & \multicolumn{4}{|c|}{ Sexual samples } & \multirow[b]{3}{*}{$A v i$} & \multirow[b]{3}{*}{ Val_2 } & \multirow[b]{3}{*}{$L R \_2$} & \multirow[b]{3}{*}{ Col_2 } & \multirow[b]{3}{*}{ Loos_2 } & \multirow[b]{3}{*}{ Val_1 } & \multirow[b]{3}{*}{$L R \_1$} & \multirow[b]{3}{*}{ Col_1 } & \multirow[b]{3}{*}{ Loos_1 } \\
\hline & \multicolumn{4}{|c|}{ Côte d'Azur } & & & & & & & & & \\
\hline & Fréj & Roq & Car & Ant & & & & & & & & & \\
\hline Fréj & & NS & NS & NS & & & & & & & & & \\
\hline Roq & -0.00 & & NS & NS & $*$ & $* * *$ & $* * *$ & $* * *$ & $* * *$ & & & & \\
\hline Car & 0.03 & 0.01 & & NS & & & & & & & & & \\
\hline Ant & 0.05 & 0.03 & -0.01 & & & & & & & & & & \\
\hline Avi & 0.03 & 0.00 & 0.03 & 0.04 & & $* * *$ & $* * *$ & $* * *$ & $* *$ & & & & \\
\hline Val_2 & 0.11 & 0.09 & 0.12 & 0.09 & 0.08 & & $* * *$ & $* * *$ & $* * *$ & $* * *$ & & & \\
\hline LR_2 & 0.15 & 0.17 & 0.21 & 0.17 & 0.14 & 0.11 & & $* * *$ & $* * *$ & & $* * *$ & & \\
\hline Col_2 & 0.01 & 0.05 & 0.09 & 0.03 & 0.05 & 0.06 & 0.08 & & $* *$ & & & NS & \\
\hline Loos_2 & 0.05 & 0.04 & 0.08 & 0.02 & 0.08 & 0.08 & 0.18 & 0.02 & & & & & NS \\
\hline Val_1̄- & & & & & & 0.03 & & & & & $* * *$ & $* * *$ & $* * *$ \\
\hline LR_1 & & & & & & & 0.08 & & & 0.04 & & $* * *$ & $* * *$ \\
\hline Col̄1 & & & & & & & & 0.02 & & 0.07 & 0.06 & & $*$ \\
\hline Loos_1 & & & & & & & & & 0.02 & 0.04 & 0.07 & 0.02 & \\
\hline
\end{tabular}

To focus on meaningful comparisons, samples from the same period or from the same location are compared. Class of first type error probabilities of absence of genotypic differentiation between samples and groups of samples are given above the diagonal. The symbols ns, ${ }^{*}$, ${ }^{* *}$, and ${ }^{* * *}$ correspond respectively to first type errors of rejecting the null hypothesis above $5 \%$ and below $5 \%, 1 \%$ and $0.1 \%$. Fst estimators for each pair of samples considered are given below the diagonal. 
on a finer scale, an isolation by time effect was observed in these two sites.

\section{Discussion}

\section{Genetic differentiation between reproductive modes}

In our study, we analysed the population structure of three groups of aphids: cyclically parthenogenetic aphids collected on peach trees (also referred to as sexual samples), and a mixture of obligately and cyclically parthenogenetic aphids collected aerially in springsummer and autumn, with more obligately parthenogenetic aphids in milder regions (ie in Valence and Le Rheu). We expected to find (1) a greater genotypic diversity, (2) less linkage disequilibrium between loci, and (3) a lower heterozygosity in cyclically than in obligately parthenogenetic populations. The two first expectations proved to be true.

In sexual samples, almost no clonal copies of genotypes were found, indicating a maximum genotypic diversity. Likewise, no linkage disequilibrium was found in aphids collected on peach trees in autumn. Therefore, sexual populations of $M$. persicae in France (present study) and in Australia (Wilson et al, 2002) have very similar genetic structures. It is noteworthy that the sexual aphids examined in our study were produced by lineages that have undergone several apomictic generations. Thus, the absence of genetic signs of clonal reproduction (repeated genotypes, linkage disequilibrium) in these samples suggests that a single sexual reproduction event in cyclically parthenogenetic clones each year is sufficient to destroy genetic fingerprints of clonality. This result resembles that found in a cyclically parthenogenetic rotifer species, Brachionus plicatilis (Müller) (Gomez and Carvalho, 2000), in which a high genotypic diversity was found despite numerous parthenogenetic generations.

The spring-summer and autumn aerial samples from Valence and Le Rheu were considered to be mainly constituted of obligately parthenogenetic aphids because they were collected in mild regions. In these samples, the incidence of clonality on genetic parameters was revealed by frequent linkage disequilibrium and a high frequency of repeated genotypes. Both indicate that clonal amplification is a major phenomenon shaping the genetic structure of aphids caught in aerial traps. This characteristic of aphid populations has also been observed in all aphid species analysed so far (eg De Barro et al, 1995; Sunnucks et al, 1997; Fenton et al, 1998; Vanlerberghe-Masutti and Chavigny, 1998; Simon et al, 1999; Wilson et al, 1999; Haack et al, 2000).

In this study, most samples of $M$. persicae showed heterozygote deficiency, and differences in heterozygosity were undetectable between sexual populations and aerial samples. Delmotte et al (2002) found significant heterozygote excess in asexual populations of $R$. padi, and showed that heterozygosity was globally higher in obligately than in cyclically parthenogenetic aphids. These authors explained these results by either an ancient loss of sexuality or a hybrid origin of asexual lineages in this species. In $M$. persicae, the absence of heterozygote excess and the slight difference of heterozygosity between sexual and aerial samples may have two explanations: (1) the time since loss of sexuality may not have been sufficient to allow the accumulation of mutations in obligately parthenogenetic aphids compared to in cyclically parthenogenetic ones; and (2) gene flow between cyclically and obligately parthenogenetic aphids through the production of males may be sufficient to prevent differences in heterozygosity between reproductive modes.

The general tendency for heterozygote deficiency found in our study may be explained by the sampling design, as all of the aphids analysed were migrating. Those caught in aerial traps were obviously migrating, and sexual individuals captured on peach trees were at the end point of the autumn migration to the primary host. Thus, these samples of aphids corresponded to pools of migrants originating from diverse populations. If those original populations were genetically differentiated, then a Wahlund effect, that is an heterozygote deficiency due to the fact that several subpopulations were pooled, is expected.

\section{Variation in reproductive mode in French $M$. persicae}

A major result of this study is that the reproductive system, that is cyclical or obligate parthenogenesis, is correlated to microsatellite variability in M. persicae at the population level. Samples caught on primary hosts (Prunus persica) can be used as a reference for sexual samples in genetic studies. Taking these samples as a reference, aerial samples from Valence and Le Rheu might mostly correspond to obligately parthenogenetic aphids, whereas most aphids caught in Colmar in autumn might generally be cyclically parthenogenetic aphids.

The autumn aerial sample collected at Colmar, in north-eastern continental France, was closer to the sexual samples in terms of genotypic diversity and linkage disequilibrium. Moreover, low Fst estimates were found between the Colmar autumn and sexual samples, and the only common genotype between sexual and aerial samples was found in the autumn flight of Colmar. Additionally, while males were very rare in Valence and Le Rheu, they were most abundant at Colmar. These results strongly suggest that autumn aerial samples are mostly constituted of obligately parthenogenetic aphids, except in Colmar where the aphids display biological and genetic characteristics of cyclically parthenogenetic individuals.

This pattern observed in flying aphids agrees with the climatic selection hypothesis proposed by Blackman (1974): Colmar is the only location among the aerial trap sites where aphids are probably cyclically parthenogenetic and it is the site where winters are most severe. Daily minimum temperatures recorded in winter 19992000 were significantly lower in Colmar $\left(0.9 \pm 0.5^{\circ} \mathrm{C}\right)$ than in Valence $\left(3.6 \pm 0.4^{\circ} \mathrm{C}\right)$, Loos-en-Gohelle $\left(2.6 \pm 0.4^{\circ} \mathrm{C}\right)$ or Le Rheu $\left(3.8 \pm 0.4^{\circ} \mathrm{C}\right)$. Furthermore, minimum temperatures reached $-12.2^{\circ} \mathrm{C}$ in Colmar in 2000, that is, more than $5^{\circ} \mathrm{C}$ less than in the other trap locations, which are considered as lethal for parthenogenetic aphids. The situation observed in our study may be close to that for R. padi. Hullé et al (1998) observed that $90 \%$ of flying female $R$. padi in autumn were cyclically parthenogenetic aphids in Colmar, whereas only $34 \%$ were cyclically parthenogenetic aphids in Le Rheu. Our results together 
with those of studies on $R$. padi (Rispe et al, 1998a) and Sitobion avenae (Dedryver et al, 2001) tend to confirm and to extend Blackman's climatic selection of sex hypothesis (1974) and its successive theoretical developments (Rispe and Pierre, 1998; Rispe et al, 1998b).

The presence of sexual aphids sampled on peach trees in warm southern locations appears to contradict the climatic hypothesis. Three explanations can be proposed: (1) these aphids may come from distant and cold locations, and therefore may have flown over long distances to reach peach trees, (2) these aphids come from close and warm locations, and thus may correspond to a small proportion of the resident individuals that are obligately parthenogenetic aphids for the vast majority; and (3) other factors are involved in the maintenance of sex that give an advantage to cyclically parthenogenetic aphids even in warm climate (Simon et al, 2002).

\section{Limited migration between distant populations of M. persicae}

Genetic differentiation between sexual samples was low and not significant over small geographic distances $(<60 \mathrm{~km})$ and low but significant on a larger geographical scale $(150-200 \mathrm{~km})$. Putatively obligately parthenogenetic aphids from aerial samples were significantly differentiated on the national scale in both periods, and differentiation was highest in autumn.

The significant population differentiation found in $M$. persicae on the regional and national scales is consistent with the results of other studies on this species. Wilson et al (2002) observed a low but significant genetic differentiation on small geographical scales $(<50 \mathrm{~km})$ in cyclically parthenogenetic $M$. persicae in Australia, and Martínez-Torres et al (1997) found significant genetic differentiation between samples of M. persicae collected nearby in Spain.

Thus, our results, together with those of previous studies, suggest that long-distance migration is not common in $M$. persicae. Genetic differentiation, even at small geographical distances, is not rare in aphids (Loxdale, 1990; Loxdale et al, 1993; Martínez-Torres et al, 1997; Sunnucks et al, 1997; Simon et al, 1999) and consequently aphid migration may be more limited than previously thought (Van Emdem et al, 1969; Taylor, 1977; Robert, 1988; Hales et al, 1997). However, it should be noted that local differentiation does not mean that intense migration and long-distance flights do not occur in aphids, but rather that long-distance migration may be rare or that the success rate of migration may be low (Loxdale et al, 1993; Loxdale and Lushai, 1999). The degree of geographical differentiation may depend on the species considered: the differentiation observed in $M$. persicae appears to be larger than that found in other aphid species. For instance, in R. padi, significant genetic differentiation was only found between populations located more than $1000 \mathrm{~km}$ apart (Delmotte et al, 2002). Low geographic differentiation was found on a large (more than $500 \mathrm{~km}$ ) and small geographic scale $(<100 \mathrm{~km})$ in the cereal aphid, S. avenae (De Barro et al, 1995; Sunnucks et al, 1997; Simon et al, 1999). This suggests that large differences in migration capacities exist between aphid species, as already discussed by Loxdale et al (1993).
Effect of reproductive mode on population differentiation The production of males by obligately parthenogenetic lineages may enable a significant gene flow with cyclically parthenogenetic aphids. However this gene flow may not be sufficient to prevent differences in some genetic characteristics related to reproductive modes (see above). We observed that the level of population differentiation between putative cyclically parthenogenetic aphids was lower than between obligately parthenogenetic ones. It is noteworthy that the number of independent samples from the two reproductive modes may not be sufficient to be categorical on this subject. However, this difference in population structure has already been found in other host alternating species of aphids (Delmotte et al, 2002). The obligate migration involved in the switch from secondary to primary hosts associated with sexual reproduction might explain this phenomenon (Delmotte et al, 2002). The primary host of $M$. persicae generally grows in southern France, but it can be found sparsely distributed further north. Therefore holocyclic migrants, generally produced in cold regions (eg north-eastern France), might have a relatively low success for finding primary hosts. Previous studies showed that the success rate for finding primary hosts is low during the flight to the winter host. For instance, Ward et al (1998) estimated that only $0.6 \%$ of the autumn migrants of $R$. padi find the primary host, Prunus padus.

Thus, the migration-selection or migration-drift balance may depend on the reproductive mode and may favour migration in cyclically parthenogenetic aphids. It would be particularly interesting to test this hypothesis because the positive association between the effect of sex and dispersal proposed here would reinforce the effect of recombination. In fact, sexual reproduction per se has an antagonistic effect on local adaptation because inter- and intrachromosomic recombination are likely to disrupt the combination of genes that have adapted to the local selection pressure (Mopper and Strauss, 1998).

\section{Temporal genetic structure as a result of selection?}

We observed a temporal genetic differentiation between samples collected in spring-summer and autumn in Valence and Le Rheu. A pattern of 'isolation by time' at a fine temporal scale was also found in these samples. This means that the temporal distribution of genotypes and/ or genes is nonrandom and that two $M$. persicae individuals collected at different periods are more likely to be genetically different than two aphids collected in a short temporal window. Temporal variability in the genetic structure of $M$. persicae populations also indicates an impoverishment through time of genetic variability: the number of alleles, genotypes, and pairs of loci in linkage equilibrium decreased from spring-summer to autumn in Valence and Le Rheu, whereas some multilocus genotypes increased in frequency. Furthermore, between sample differentiation increased sharply between summer and autumn, suggesting that the genetic compositions of the samples varied in time and that these variations were different between populations.

This result may be explained by the existence of 'clonal explosions' that take place within a short period of time as a consequence of stochastic or deterministic factors, as suggested by Wilson et al (2002) to account for population differentiation in $M$. persicae. Drift and selection can 
both explain this temporal variation in genetic variability (Wright, 1969). However, in the case of aphid species like $M$. persicae, the size of the populations during the parthenogenetic phase can be considerable. This reduces the probability of drift and reinforces the hypothesis of selection. Gomez and Carvalho (2000) also observed a temporal variation in the genotypic composition of the cyclically parthenogenetic rotifer, Brachionus plicatilis, during the parthenogenetic phase and also interpreted this phenomenon as clonal selection rather than drift.

In this context of selection, agricultural practices, especially insecticide treatments, are likely to act as important selective forces on $M$. persicae populations. Insecticide resistance alleles are known to be selected in natural populations of this species (Devonshire et al, 1999) in response to various chemical treatments. Cyclic temporal dynamics of selected genotypes depending on cyclic variations in selection have been observed in other insect species like the mosquito Culex pipiens (L.) (Lenormand et al, 1999). Muggleton et al (1996) showed that the frequency of an insecticide resistance mechanism, the overproduction of esterase, in $M$. persicae in the UK follows cyclic dynamics, probably corresponding to alternating periods of intense selection in summer and counterselection of resistant genotypes in winter (see also Foster et al, 2000, 2002).

\section{Conclusion}

The results of this microsatellite analysis show that the reproductive mode polymorphism in $M$. persicae is detectable at the population level. As expected, the major difference between cyclically and obligately parthenogenetic populations concerns genotypic variability, with cyclically parthenogenetic aphids being the most variable. Populations of $M$. persicae in France may be genetically structured by at least three factors: (1) limited migration that is not sufficient to homogenise the genetic structures of populations on a national scale in obligately parthenogenetic aphids, (2) the geographic distribution of reproductive modes, and probably (3) the effect of strong selection other than climate that causes geographic and temporal genetic differentiation. As asexual reproduction occurs most of the year in $M$. persicae, strong selective forces together with the absence of genetic recombination may have major effects on the 'neutral' population genetic structure: departure from $\mathrm{H}-\mathrm{W}$ equilibrium, strong linkage disequilibrium, overrepresentation of some clones, local genetic differentiation, and temporal differentiation can all occur as a result of these forces. In the case of insecticide treatments, a combined analysis of microsatellites and insecticide resistance genes would be of great interest to quantify the relative importance of selection and drift on 'neutral' genetic variability.

\section{Acknowledgements}

We thank M Hullé for permission to use Agraphid samples and the trap operators for their precious work. We are grateful to F Vanlerberghe-Masutti, L Lapchin, X Fauvergue and D Forcioli for their advice and comments during this work. We also thank Gavin Malarky, Roger Blackman, Paul Sunnucks and Alex Wilson for sharing unpublished microsatellites of aphids. Part of this work was financed by the Department 'Santé des Plantes et Environnement' of the Institut National de la Recherche Agronomique.

\section{References}

Blackman RL (1972). The inheritance of life-cycle differences in Myzus persicae (Sulz.) (Hem., Aphididae). Bull Entomol Res 62 281-294.

Blackman RL (1974). Life-cycle variation of Myzus persicae (Sulz.) (Hom., Aphididae) in different parts of the world, in relation to genotype and environment. Bull Entomol Res 63: 595-607.

Blackman RL, Eastop VF (1984). Aphids on the World's Crops: An Identification Guide. John Wiley \& Sons: Chichester.

Butlin RK (2000). Virgin rotifers. Trends Ecol Evol 15: 389-390.

De Barro PJ, Sherratt TN, Carvalho GR, Nicol D, Itengar A, MacLean N (1995). Geographic and microgeographic genetic differentiation in two aphid species over southern England using the multilocus (GATA)4 probe. Mol Ecol 4: 375-382.

Dedryver C-A, Hullé M, Le Gallic J-F, Caillaud MC, Simon J-C (2001). Coexistence in space and time of sexual and asexual populations of the cereal aphid Sitobion avenae. Oecologia 128 : 379-388.

Delmotte F, Leterme N, Gauthier J-P, Rispe C, Simon J-C (2002). Genetic architecture of sexual and asexual populations of the aphid Rhopalosiphum padi based on allozyme and microsatellite markers. Mol Ecol 11: 711-723.

Devonshire AL, Field LM, Foster SP, Moores GD, Williamson M, Blackman RL (1999). The evolution of insecticide resistance in the peach-potato aphid, Myzus persicae. In: Denholm I, Picket JA, Devonshire AL (eds) Insecticide Resistance: From Mechanisms to Management, CABI Publishing: Wallingford. pp 1-8.

Fenton B, Woodford JA, Malloch G (1998). Analysis of clonal diversity of the peach-potato aphid, Myzus persicae (Sulzer), in Scotland, UK and evidence for the existence of a predominant clone. Mol Ecol 7: 1475-1487.

Foster SP, Denholm I, Devonshire AL (2000). The ups and down of insecticide resistance in peach-potato aphids (Myzus persicae) in the UK. Crop Prot 19: 873-879.

Foster SP, Harrington R, Dewar AM, Denholm I, Devonshire AL (2002). Temporal and spatial dynamics of insecticide resistance in Myzus persicae (Hemiptera: Aphididae). Pest Manage Sci 58: 895-907.

Gomez A, Carvalho GR (2000). Sex, parthenogenesis and genetic structure of rotifers: microsatellite analysis of contemporary and resting egg bank populations. Mol Ecol 9: 203-214.

Haack L, Simon J-C, Gauthier J-P, Plantegenest M, Dedryver CA (2000). Evidence for predominant clones in a cyclically parthenogenetic organism provided by a combined demographic and genetic analyses. Mol Ecol 9: 2055-2066.

Hales D, Tomiuk J, Wöhrmann K, Sunnucks P (1997). Evolutionary and genetic aspect of aphid biology: a review. Eur J Entomol 94: 1-55.

Hebert PDN (1981). Obligate asexuality in Daphnia. Am Nat 117: 784-789.

Hullé M (1991). Agraphid, un réseau de surveillance des populations de pucerons: base de données associée et domaines d'application. Ann ANPP 2: 103-113.

Hullé M, Simon JC, Lourgant K, Pannetier D (1998). Biological and molecular characterisation of the autumn migrants of the bird cherry-oat aphid, Rhopalosiphum padi. Bull OILB/SROP 21: $1-5$.

Judson OP, Normark BB (2000). Sinless originals. Science 288: 1185-1186.

Lenormand T, Bourguet D, Guillemaud T, Raymond M. (1999). Tracking the evolution of insecticide resistance in the mosquito Culex pipiens. Nature 400: 861-864.

Llewellyn, KS, Loxdale, HD, Brookes, CP, Clark, SJ, Sunnucks, P (2003). Migration and genetic structure of the grain aphid 
(Sitobion avenae) in Britain related to climate and clonal fluctuation as revealed using microsatellites. Molecular Ecology 12: 21-34.

Loxdale HD (1990). Estimating levels of gene flow between natural populations of cereal aphids (Homoptera: Aphididae). Bull Entomol Res 80: 331-338.

Loxdale HD, Hardie J, Halbert SE, Foottit RG, Kidd AC, Carter CI (1993). The relative importance of short- and long-range movement in flying aphids. Biol Rev 68: 291-311.

Loxdale HD, Lushai G (1999). Slaves of the environment: the movement of herbivorous insects in relation to their ecology and genotype. Philos Trans $R$ Soc Lond B 354: 1479-1495.

Mark Welch DM, Meselson M (2000). Evidence for evolution of Bdelloid rotifers without sexual reproduction or genetic exchange. Science 288: 1211-1215.

Martínez-Torres D, Carrió R, Latorre A, Simon JC, Hermoso A, Moya A (1997). Assessing the nucleotide diversity of three aphid species by RAPD. J Evol Biol 10: 459-477.

Maynard Smith J (1998). Evolutionary Genetics. Oxford University Press: Oxford.

Mopper S, Strauss S (1998). Genetic Structure and Local Adaptation in Natural Insect Populations: Effects of Ecology, Life History, and Behavior. Chapman \& Hall: New York.

Muggleton J, Hockland S, Thind BB, Lane A, Devonshire AL (1996). Long term stability in the frequency of insecticide resistance in the peach-potato aphid, Myzus pesicae. In: BCPC (ed) Brighton Crop Protection Conference - Pests and Diseases, London. pp 739-744.

Normark BB (1999). Evolution in a putatively ancient asexual aphid lineage: recombination and rapid karyotype change. Evolution 53: 1458-1469.

Raymond M, Rousset F (1995a). Genepop (version. 1.2), a population genetics software for exact tests and ecumenicism. J Heredity 86: 248-249.

Raymond M, Rousset F (1995b). An exact test for population differentiation. Evolution 49: 1280-1283.

Rispe C, Pierre J-S (1998). Coexistence between cyclical parthenogens, obligate parthenogens and intermediates in a fluctuating environment. J Theor Biol 195: 97-110.

Rispe C, Hullé M, Gauthier J-P, Pierre J-S, Harrington R (1998a). Effect of climate on the proportion of males in the autumn flight of the aphid Rhopalosiphum padi L. (Hom. Aphididae). J Appl Entmol 122: 129-136.

Rispe C, Pierre J-S, Simon J-C, Gouyon P-H (1998b). Models of sexual and asexual coexistence in aphids based on constraints. J Evol Biol 11: 685-701.

Robert Y (1988). Dispersion and migration. In: Minks AK, Harrewijn P (eds) Aphids: Their Biology, Natural Enemies and
Control, Vol. 2A: World Crop Prests, Elsevier: Amsterdam. pp 299-313.

Simon JC, Baumann S, Sunnucks P, Hebert PD, Pierre JS, Le Gallic JF et al (1999). Reproductive mode and population genetic structure of the cereal aphid Sitobion avenae studied using phenotypic and microsatellite markers. Mol Ecol 8: 531545.

Simon J-C, Leterme N, Delmotte F, Martin O, Estoup A (2001). Isolation and characterization of microsatellite loci in the aphid species, Rhopalosiphum padi. Mol Ecol Notes 1: 4-5.

Simon J-C, Rispe C, Sunnucks P (2002). Ecology and evolution of sex in aphids. Trends Ecol Evol 17: 34-39.

Sloane M, Sunnucks P, Wilson ACC, Hales DF (2001). Microsatellite isolation, linkage group identification and determination of frequency in the peach-potato aphid, Myzus persicae (Sulzer) (Hemiptera: Aphididae). Genet Res 77: 251-260.

Sokal RR, Rohlf FJ (1995). Biometry. W.H. Freeman and Company: New York.

Sunnucks P, De Barro PJ, Lushai G, Maclean N, Hales D (1997). Genetic structure of an aphid studied using microsatellites: cyclic parthenogenesis, differentiated lineages and host specialization. Mol Ecol 6: 1059-1073.

Sunnucks P, Hales DF (1996). Numerous transposed sequences of mitochondrial cytochrome oxidase I-II in aphids of the genus Sitobion (Hemiptera: Aphididae). Mol Biol Evol 13: 510524.

Taylor LR (1977). Migration and the spatial dynamics of an aphid, Myzus persicae. J Anim Ecol 46: 411-423.

Van Emdem HF, Eastop VF, Way MJ (1969). The ecology of Myzus persicae. Ann Rev Entomol 14: 197-270.

Vanlerberghe-Masutti F, Chavigny P (1998). Host-based genetic differentiation in the aphid Aphis gossypii Glover, evidenced from RAPD fingerprints. Mol Ecol 7: 905-914.

Ward SA, Leather SR, Pickup J, Harrington R (1998). Mortality during dispersal and the cost of host-specificity in parasites: how many aphids find hosts? J Anim Ecol 67: 763-773.

Weir BS, Cockerham C (1984). Estimating F-statistics for the analysis of population structure. Evolution 38: 1358-1370.

Wilson ACC, Sunnucks P, Blackman RL, Hales DF (2002). Microsatellite variation in cyclically parthenogenetic populations of Myzus persicae in south-eastern Australia. Heredity 88: 258-266.

Wilson ACC, Sunnucks P, Hales DF (1999). Microevolution, low clonal diversity and genetic affinities of parthenogenetic Sitobion aphids in New Zealand. Mol Ecol 8: 1655-1666.

Wright S (1969). Evolution and the Genetics of Populations. University of Chicago Press: Chicago, IL. 